\title{
TMEM16B, A Novel Protein with Calcium-Dependent Chloride Channel Activity, Associates with a Presynaptic Protein Complex in Photoreceptor Terminals
}

\author{
Heidi Stöhr, ${ }^{1}$ Julia B. Heisig, ${ }^{1}$ Peter M. Benz, ${ }^{3}$ Simon Schöberl, ${ }^{2}$ Vladimir M. Milenkovic, ${ }^{2}$ Olaf Strauss, ${ }^{2}$ \\ Wendy M. Aartsen, ${ }^{4}$ Jan Wijnholds, ${ }^{4}$ Bernhard H. F. Weber, ${ }^{1}$ and Heidi L. Schulz \\ ${ }^{1}$ Institut für Humangenetik, Universität Regensburg, and ${ }^{2}$ Experimentelle Ophthalmologie, Klinik und Poliklinik für Augenheilkunde, Klinikum der \\ Universität Regensburg, 93053 Regensburg, Germany, ${ }^{3}$ Physiologisches Institut der Universität Würzburg, 97070 Würzburg, Germany, and ${ }^{4}$ Department \\ of Neuromedical Genetics, The Netherlands Institute for Neuroscience, Royal Netherlands Academy of Arts and Sciences, 1105 BA Amsterdam, \\ The Netherlands
}

Photoreceptor ribbon synapses release glutamate in response to graded changes in membrane potential evoked by vast, logarithmically scalable light intensities. Neurotransmitter release is modulated by intracellular calcium levels. Large $\mathrm{Ca}^{2+}$-dependent chloride currents are important regulators of synaptic transmission from photoreceptors to second-order neurons; the molecular basis underlying these currents is unclear. We cloned human and mouse TMEM16B, a member of the TMEM16 family of transmembrane proteins, and show that it is abundantly present in the photoreceptor synaptic terminals in mouse retina. TMEM16B colocalizes with adaptor proteins PSD95, VELI3, and MPP4 at the ribbon synapses and contains a consensus PDZ class I binding motif capable of interacting with PDZ domains of PSD95. Furthermore, TMEM16B is lost from photoreceptor membranes of MPP4-deficient mice. This suggests that TMEM16B is a novel component of a presynaptic protein complex recruited to specialized plasma membrane domains of photoreceptors. TMEM16B confers $\mathrm{Ca}^{2+}$-dependent chloride currents when overexpressed in mammalian cells as measured by halide sensitive fluorescent protein assays and whole-cell patch-clamp recordings. The compartmentalized localization and the electrophysiological properties suggest TMEM16B to be a strong candidate for the long sought-after $\mathrm{Ca}^{2+}$-dependent chloride channel in the photoreceptor synapse.

\section{Introduction}

The visual system in vertebrates has developed special properties to operate in a wide range of different wavelengths and light intensities. Light is captured by photosensitive pigments in photoreceptors and activates the phototransduction cascade ultimately resulting in hyperpolarization of the photoreceptor outer segment membrane. The electrical signal then spreads to the inner segment and synaptic terminal where it gates finely graded changes in the rate of glutamate neurotransmitter release from synaptic vesicles onto second-order neurons. The tonic release of glutamate is dependent on the intracellular calcium concentration. In darkness, vertebrate photoreceptors are depolarized to membrane potentials near $-40 \mathrm{mV}$. This triggers continuous release of glutamate by $\mathrm{Ca}^{2+}$ influx through L-type voltage-gated calcium channels. Suppression of synaptic vesicle exocytosis during light-evoked hyperpolarization occurs in a continuous manner and is achieved by the closure of calcium channels and efficient removal of cytosolic $\mathrm{Ca}^{2+}$. The rate of neurotransmitter

Received Nov. 19, 2008; revised April 7, 2009; accepted April 20, 2009.

This work was supported by grants from the Deutsche Forschungsgemeinschaft (ST0366/2-2) and from the Bundesministerium für Bildung und Forschung (01KW9921). We thank Maria Vögerl for performing the yeast two-hybrid assays.

Correspondence should be addressed to Dr. Heidi Stöhr, Institute of Human Genetics, University of Regensburg, Franz-Josef-Strauss-Allee 11, 93053 Regensburg, Germany. E-mail: heidi.stoehr@klinik.uni-regensburg.de. DOI:10.1523/JNEUROSCI.5546-08.2009

Copyright $\odot 2009$ Society for Neuroscience $\quad$ 0270-6474/09/296809-10\$15.00/0 release in photoreceptors is remarkably sensitive to changes in the presynaptic membrane potential and intracellular calcium concentration (Copenhagen et al., 1990; Rieke and Schwartz, 1996). Numerous processes are therefore required to regulate intracellular $\mathrm{Ca}^{2+}$ homeostasis. This includes $\mathrm{Ca}^{2+}$ buffering systems like $\mathrm{Ca}^{2+}$ sequestration and release from internal stores (Krizaj and Copenhagen, 2002; Suryanarayanan and Slaughter, 2006), $\mathrm{Ca}^{2+}$ extrusion by plasma membrane $\mathrm{Ca}^{2+}$ ATPases (PMCAs) (Morgans et al., 1998) and modulation of $\mathrm{Ca}^{2+}$-dependant inactivation (Zühlke et al., 1999; Singh et al., 2006). Furthermore, additional membrane conductances like large $\mathrm{Ca}^{2+}$-activated chloride currents have been measured in photoreceptors (Bader et al., 1982; Maricq and Korenbrot, 1988; Cia et al., 2005). The interaction between $\mathrm{Ca}^{2+}$ currents and $\mathrm{Ca}^{2+}$-activated chloride currents is believed to regulate synaptic output by local feedback mechanisms (Thoreson et al., 2003; Thoreson and Bryson, 2004); however, the molecular identity of $\mathrm{Ca}^{2+}$-activated chloride channels (CaCCs) in photoreceptors is currently unknown.

Recently, we and others have described a presynaptic protein complex in photoreceptors consisting of the cytoplasmic adaptor proteins MPP4, PSD95, and VELI3 that may also include PMCAs and the $\mathrm{Ca}^{2+}$-binding protein recoverin (Stöhr et al., 2005; Aartsen et al., 2006; Yang et al., 2007; Förster et al., 2009). MPP4 appears to hold a key scaffolding function in the recruitment and assembly of this complex as mice lacking MPP4 are characterized 
by an absence of PSD95, VELI3, and PMCAs from the ribbon synapse (Aartsen et al., 2006; Yang et al., 2007).

In the present study, we report the identification and characterization of TMEM16B, another component of the photoreceptor presynaptic scaffold that is lost from MPP4-deficient photoreceptors. We show that the intracellular $\mathrm{C}$ terminus of TMEM16B serves as a ligand for PDZ domains of PSD95. In addition, we demonstrate that TMEM16B possesses CaCC activity when expressed in mammalian cells, similar to its close relative TMEM16A (Caputo et al., 2008; Schroeder et al., 2008; Yang et al., 2008). Together, these data strongly indicate that the $\mathrm{Ca}^{2+}$ activated chloride current known to be present in photoreceptor terminals is evoked by TMEM16B activity.

\section{Materials and Methods}

Cloning of TMEM16B. Nucleotide and protein sequence homology searches were done using the Blat program from the University of California, Santa Cruz Genome Browser website (http://genome.ucsc.edu/). To identify the $5^{\prime}$ end of human TMEM16B cDNA, reverse transcription (RT)-PCR was performed using total RNA isolated from human retina and primers A126-a (5'-GCCTACCTTATCAATATAGGA-3'), A126-b (5'-GGTCCGCGTCCACATCATG-3') and A126R7 (5'-AATGCTGCCTCCTGCTT TGA-3'). The full-length coding sequence of mouse Tmem $16 b$ was RT-PCR amplified from mouse retinal RNA with primer pair mA126-F10 (5'-GGGGTACCATCTGGGGACCAGCA CCATG-3')/mA126-R13 (5'-CCGGTACCTCATACATTGGTGTGCT GGGACC- $\left.3^{\prime}\right)$. PCR products were sequenced and cloned into the KpnI site of pcDNA3 (Invitrogen) or pCEP1.4 vector in-frame with a C-terminal rhodopsin (Rho)-1D4 tag (Stöhr et al., 2005) for expression in mammalian cells. The human and mouse cDNA sequences reported in this manuscript have been deposited in GenBank under the accession numbers FJ384095 and FJ384096.

RNA expression analysis. Frozen retinas dissected from human donor eyes obtained from the University Eye Clinic in Würzburg (Germany) as well as retina, retinal pigment epithelium, bladder, colon, heart, kidney, liver, lung, spleen, stomach and brain tissues from adult C57BL/6 mice were used to extract total RNA with the RNeasy Mini Kit (Qiagen). The human total RNA master panel was purchased from BD Biosciences Clontech. RT-PCRs were performed with primer pair A126F2 (5'CATCATTCCTCATCCCA TC-3')/A126R (5'-GAGGCAAAGTTC ATCAGG-3') for human TMEM16B and Tmem16b-F1 (5'CACAACGGGACACTACATGG-3')/Tmem16b-R1 (5'-CTTAAGCC AGTTCCCAGCA G-3') for mouse Tmem16b as previously described (Stöhr et al., 2002). Primers specific for constitutively expressed housekeeping genes glyceraldehyde-3-phosphate dehydrogenase (G3PDH) and $\beta$-glucuronidase (Gusb) have been described previously (Stöhr et al., 2000, 2002).

Antibodies. A polyclonal anti-TMEM16B antiserum (TMEM16B-303) was generated in rabbits immunized with GST-TMEM16B-C-term fusion proteins (amino acids 950-1002) and purified using HiTrap NHSactivated Sepharose HP columns (GE Healthcare) as described previously (Stöhr et al., 2005). For anti-TMEM16B monoclonal antibody production, mice were immunized with a GST-TMEM16B-N-term fusion protein (amino acids 14-134) mixed with ImmunEasy Mouse Adjuvant (Qiagen). The spleen of a mouse showing strong immune response was used for cell fusion with NS-1 myeloma cells. Hybridomas secreting specific antibodies against TMEM16B (TMEM16B-7H10) were cloned by limiting dilution. Western blot analysis to demonstrate specificity of the TMEM16B antibodies were performed with MBP fusion proteins containing the respective $\mathrm{N}$ - and $\mathrm{C}$-terminal TMEM16B protein fragments and total proteins extracted from mouse tissues as described previously (Stöhr et al., 2003). Polyclonal rabbit antibodies against MPP4 have been reported previously (van de Pavert et al., 2004). Polyclonal rabbit antibodies against PSD95 and synaptophysin were purchased from Synaptic Systems, monoclonal mouse antibodies against PSD95 (clone 7E3-1B8) were from Affinity Bioreagents, and polyclonal rabbit antibodies against Veli3 were from Zymed. Secondary antibodies in- cluded IgGs conjugated to horseradish peroxidase (Calbiochem) and IgGs conjugated to Alexa 488 or Alexa 594 (Invitrogen).

Transfection. 293-EBNA cells (Invitrogen) were maintained in DMEM supplemented with 10\% FCS, 2 mM L-glutamine, and $250 \mu \mathrm{g} / \mathrm{ml} \mathrm{G} 418$. Transient transfection of 293-EBNA cells was performed as described previously (Stöhr et al., 2003). Cells were solubilized in PBS/1\% Triton $\mathrm{X}-100$ or $\mathrm{PBS} / 1 \% \mathrm{SDS}$ for $30 \mathrm{~min}$ at $4^{\circ} \mathrm{C}$. After centrifugation at 100.000 $\times \mathrm{g}$ for $10 \mathrm{~min}$, the supernatant and pellet were retained for SDS-PAGE gel electrophoresis. For immunofluorescence microscopy, cells were grown on laminin-coated coverslips, fixed in $4 \%$ paraformaldehyde for $10 \mathrm{~min}$, and immunolabeled as described below.

Enzymatic glycosylation. TMEM16B-1D4 proteins were immunoprecipitated with Rho-1D4 antibodies as described previously (Förster et al., 2008). For glycosidase digestion, $10 \mu \mathrm{l}$ of immunoprecipitated protein was incubated for $4 \mathrm{~h}$ at $37^{\circ} \mathrm{C}$ with either Endo $\mathrm{H}$ or PNGase F according to the manufacturer's recommendation (NEB). Enzymes were substituted with water in control reactions. Enzymatic reactions were stopped by the addition of $1 \times$ Laemmli loading buffer and analyzed by Western blotting.

Immunohistochemistry. All animals were treated according to guidelines established at the institutions in which the experiments were performed and approved by the Animal Care and Use Committee. MPP4deficient mice have been described previously (Aartsen et al., 2006). Mutant and wild-type C57BL/6 mice were killed by $\mathrm{CO}_{2}$ asphyxiation. Enucleated mouse eyes were washed in $0.1 \mathrm{M}$ phosphate buffer $(\mathrm{PB}[\mathrm{pH}$ 7.4]), cryoprotected in $0.1 \mathrm{M} \mathrm{PB}$ containing $18 \%$ sucrose, and embedded in OCT embedding medium (Tissue-Tek). Frozen eyecups were cryosectioned vertically at $10 \mu \mathrm{m}$ and fixed in $2 \%$ paraformaldehyde in $0.1 \mathrm{M} \mathrm{PB}$ for $10 \mathrm{~min}$. Immunofluorescence labeling was performed as described previously (Stöhr et al., 2005). Each immunolabeling experiment was performed on eye sections from at least two animals. Labeled specimen were examined under an Axioskop-2 mot plus fluorescence microscope (Zeiss). Image processing was achieved with the Axiovision software version 3.1 with integrated Z-stack, three-dimensional deconvolution and extended focus modules (Zeiss). Sections from MPP4 knock-out mice were visualized by confocal laser-scanning microscopy (Zeiss 501) and the images were processed with LSM image browser version 3.2 (Zeiss).

GST-pulldown assay. Mammalian expression constructs of MPP4, VELI3, and PSD95 have been reported previously (Stöhr et al., 2005; Förster et al., 2009). Transfected 293-EBNA cells were solubilized in TBS (20 mm Tris pH 7.4, 0.15 M NaCl)/1\% Triton X-100 supplemented with complete protease inhibitor cocktail tablets (Roche Applied Sciences) for $30 \mathrm{~min}$ and centrifuged at $16.000 \times \mathrm{g}$ for $15 \mathrm{~min}$ at $4^{\circ} \mathrm{C}$. For GSTpulldown assays, cell lysates were incubated with GST (control), GSTTMEM16B-C-term (amino acids 950-1002), or GST-TMEM16B-Cterm $\Delta 3$ (amino acids 950-999) proteins immobilized on glutathioneSepharose beads for $1 \mathrm{~h}$ at $4^{\circ} \mathrm{C}$. After several washes with $\mathrm{TBS} / 0.1 \%$ Triton X-100, bound proteins were eluted with $1 \times$ Laemmli loading buffer and analyzed by immunoblotting.

Cellular YFP-I152L fluorescence measurement. Construct pEYFP-I152L for the expression of halide-sensitive yellow fluorescent protein (YFP) was kindly provided by Dr. A. Verkman from University of California, San Francisco, San Francisco, CA. HEK293 cells grown on $18 \mathrm{~mm}$ glass coverslips were transfected with pEYFP-I152L alone or in combination with TMEM16B in pcDNA3. Cells were mounted under an inverted microscope (Zeiss) and were continuously perfused with Ringer solution (mM) $\left(145 \mathrm{NaCl}, 0.4 \mathrm{KH}_{2} \mathrm{PO}_{4}, 1.6 \mathrm{~K}_{2} \mathrm{HPO}_{4}\right.$, $1.3 \mathrm{Ca}$-gluconate, $1 \mathrm{MgCl}_{2}, 5$ glucose, $\mathrm{pH}$ 7.2) at room temperature. Cells were excited at $500 \mathrm{~nm}$ using a polychromatic illumination system for microscopic fluorescence measurements (VisiChrome, Visitron Systems) and light emission was measured at $535 \pm 15 \mathrm{~nm}$. Images were acquired with a Coolsnap HQ CCD camera (Roper Scientific) and processed with MetaFluor software (Visitron Systems). Cells were exposed to $20 \mathrm{~mm} \mathrm{NaI}$ by replacing equimolar $\mathrm{NaCl}$ and maintaining the total concentration of $\mathrm{NaCl}$ plus $\mathrm{NaI}$ at 145 mM. Fluorescence intensity was measured on groups of 5-20 transfected cells. Fluorescence quenching induced by $\mathrm{I}^{-}$influx is expressed in terms of the maximal rate of fluorescence decrease $(\Delta \mathrm{RF} / \Delta t)$ and is given as absolute values. Intracellular $\mathrm{Ca}^{2+}$ concentration was increased by addition of $1 \mu \mathrm{M}$ ionomycin. Ringer solution containing $100 \mu \mathrm{M} 4,4^{\prime}$ - 


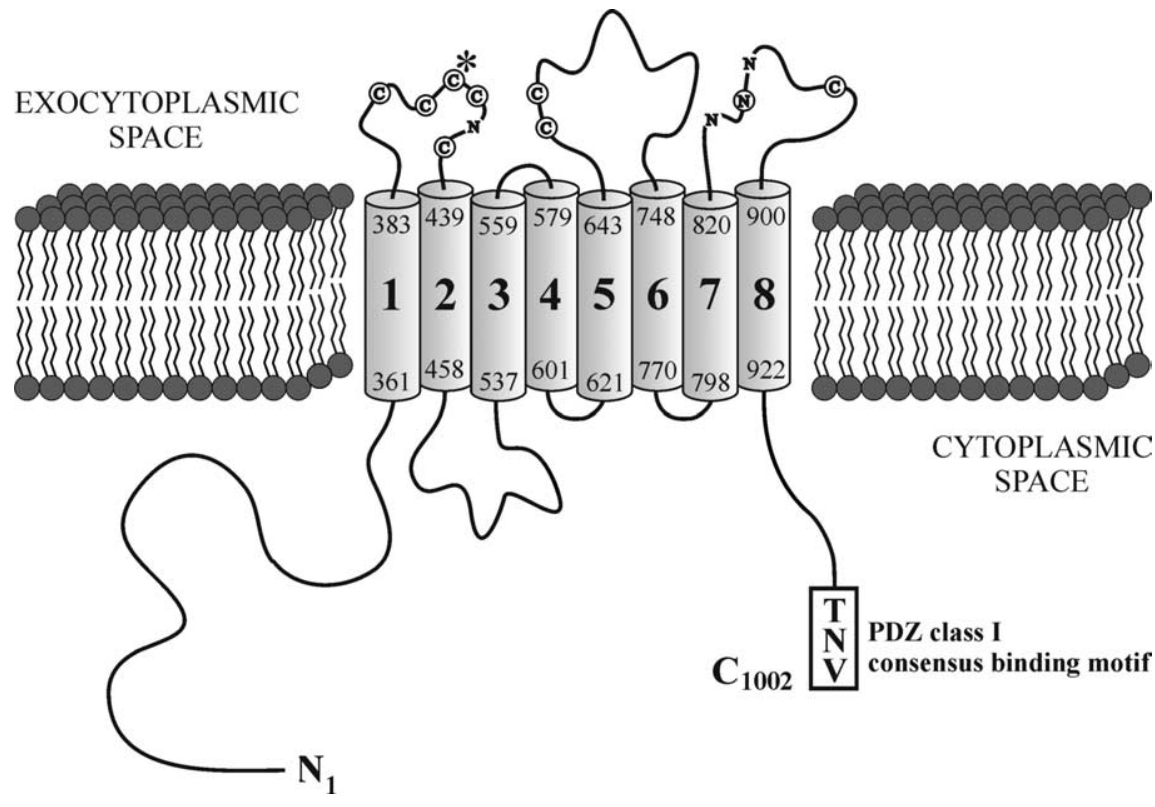

Figure 1. Topological model of TMEM16B. TMEM16B contains eight putative transmembrane segments indicated as gray cylinders. The large $\mathrm{N}$-terminal domain and the $\mathrm{C}$ terminus with the conserved PDZ class I binding motif are predicted to be present in the cytoplasmic space. Cysteine residues that are highly conserved among the TMEM16 protein family are encircled. Mutation of one of these cysteines (asterisk) in the TMEM16E paralog causes gnathodiaphyseal dysplasia 1. The positions of four N-linked glycosylation sites in the first and third extracellular loop are indicated; the encircled one is highly conserved among the TMEM16 paralogues.

diisothiocyano-2,2'-stilbene disulphonic acid (DIDS) was added $5 \mathrm{~min}$ before ionomycin application.

Patch-clamp recordings. HEK293 cells seeded on glass coverslips were transfected with YFP and TMEM16B expression constructs (both in pcDNA3). Whole-cell recordings were performed at room temperature on single cells showing YFP positive fluorescence. Cells were superfused with Ringer bath solution. To examine $\mathrm{Cl}^{-}$selectivity of whole-cell currents a low- $\mathrm{Cl}^{-}$-Ringer solution was used (mM) $(30 \mathrm{NaCl}, 115 \mathrm{Na}$ gluconate, $0.4 \mathrm{KH}_{2} \mathrm{PO}_{4}, 1.6 \mathrm{~K}_{2} \mathrm{HPO}_{4}, 1.3 \mathrm{Ca}$-gluconate, $1 \mathrm{MgCl}_{2}, 5$ glucose, $\mathrm{pH}$ 7.2). Patch pipettes with a pipette resistance of 3-5 $\mathrm{M} \Omega$ were pulled from borosilicate glass tubes using a Zeitz DMZ Universal Puller (Zeitz). Pipette solution contained $95 \mathrm{~mm} \mathrm{K-gluconate,} 30 \mathrm{~mm} \mathrm{KCl}, 4.8$ $\mathrm{mM} \mathrm{Na}_{2} \mathrm{HPO}_{4}, 1.2 \mathrm{~mm} \mathrm{NaH}_{2} \mathrm{PO}_{4}, 0.81 \mathrm{~mm}$ Ca-gluconate, 1 mm EDTA, 5 mu glucose, 3 mM ATP, $\mathrm{pH}$ 7.2. The final concentration of $\mathrm{Ca}^{2+}$ in the pipette solution was $100 \mathrm{~nm}$ to avoid activation of $\mathrm{Ca}^{2+}$-dependent $\mathrm{K}^{+}$channels. Whole-cell currents were measured using an EPC 10 patchclamp amplifier and TIDA software (both HEKA Electronics). Currents were filtered at $2.9 \mathrm{kHz}$ with a low-pass Bessel filter. The cells showed a membrane capacitance of $22.4 \pm 4.3 \mathrm{pF}(n=7)$ and an access resistance of $16.8 \pm 2.5 \mathrm{M} \Omega(n=7)$. The access resistance was compensated to values lower than $10 \mathrm{M} \Omega$. Voltages measured in experiments using Ringer solution were corrected for liquid junction potential $(9.4 \mathrm{mV})$. Liquid junction potential measured in low- $\mathrm{Cl}^{-}$-Ringer was $0 \mathrm{mV}$.

Statistics. Values are \pm SEM for the indicated number of independent measurements $(n)$. Statistical analyses were performed using one-way ANOVA. $p$ values of $<0.05$ were considered to be significant.

\section{Results}

\section{Isolation of TMEM16B cDNA}

Numerous proteins that are highly specialized in their function are required to transform light energy into electric impulses and to further transmit these signals to the brain where they are processed and perceived as vision. We previously reported the systematic expression analysis of UniGene EST clusters highly enriched in ESTs from retinal cDNA libraries to identify novel genes that are crucial in normal retinal physiology and may therefore be causally associated with retinal disease (Stöhr et al., 2000).
Sequence-tagged site G65694 initially developed from retina EST-enriched UniGene cluster Hs. 64616 was found to match the 3717 bp mRNA for chromosome 12 open reading frame 3 (C12ORF3; GenBank acc. no. AJ272204) from position 1443 to 1688 . Further analyses of nucleotide databases identified a single retinal EST sequence (GenBank acc. no. H84977) that overlapped with C12ORF3 but possessed a unique $13 \mathrm{bp}$ stretch at its $5^{\prime}$ end residing within intron 1 of C12ORF3. This suggested that two different first exons, named exon $1 \mathrm{a}$ and $1 \mathrm{~b}$, are used to generate the C12ORF3 and H84977 sequences, respectively (supplemental Fig. $1 A$, available at www.jneurosci.org as supplemental material). RT-PCR using forward primer A126-1b matching exon $1 \mathrm{~b}$ and reverse primer A126R7 located in exon 5 of C12ORF3 amplified a $682 \mathrm{bp}$ fragment from human retinal RNA. Sequencing confirmed that this cDNA was generated by splicing of exon $1 \mathrm{~b}$ to exons 2, 3, 4 and 5 of C12ORF3. RT-PCR with forward primer A126-1a positioned in exon $1 \mathrm{a}$ and reverse primers situated in exon 5 or exon 6 of C12ORF3, however, failed to produce PCR products from human retinal RNA. From this we concluded that the 3673-bp transcript containing exon $1 \mathrm{~b}$ is the major splice variant in human retina. Amino acid translation of the cDNA sequence revealed an ORF of 3028 bp with a first potential in-frame translation initiation codon, ATG, in exon $1 \mathrm{~b}$. The protein predicted from the ORF consists of 1003 aa residues with a calculated molecular mass of $113.9 \mathrm{kDa}$ and an isoelectric point of 6.12. Apart from seven $\mathrm{N}$-terminal amino acids encoded by exon $1 \mathrm{~b}$, it is identical to the reference protein sequence of TMEM16B (GenBank acc. no. NP_065106), a member of the TMEM16 family of integral membrane proteins with eight putative transmembrane domains (Fig. 1).

To identify the full-length cDNA sequence of the mouse orthologue, the human TMEM16B cDNA sequence was used to search for homologous sequences in nucleotide databases. Two overlapping cDNA clones (GenBank acc. nos. AK044763 and BC033409) with high similarity to TMEM16B were assembled to obtain the 3942 bp full-length mouse Tmem $16 b$ cDNA sequence. Tmem 16b possesses an ORF of $3063 \mathrm{bp}$ that encodes a putative protein of $1002 \mathrm{aa}$. The presence of an in-frame stop codon $60 \mathrm{bp}$ upstream of the putative start codon indicates that the entire coding region has been isolated. Pairwise alignment of the human and mouse TMEM16B protein sequences revealed an overall 94\% similarity and 92\% amino acid identity (supplemental Fig. $1 B$, available at www.jneurosci.org as supplemental material).

\section{Expression of TMEM16B and Tmem16b transcripts}

Semiquantitative RT-PCR analysis in 20 different human adult and fetal tissues revealed strong amplification of TMEM16B cDNA fragments in the retina (Fig. $2 A$ ) further supporting our previous data on exclusive retinal expression of TMEM16B in a cDNA panel consisting of nine different human tissues (Stöhr et al., 2000). Similarly, abundant Tmem16b expression was observed in mouse retina (Fig. $2 \mathrm{~B}$ ). Amplification products with significantly lower levels of intensity were also observed in other mouse neuronal tissues including retinal pigment epithelium 
(RPE), olfactory bulb, total brain, and cortex. Moderate levels of mouse Tmem16b expression in RNA samples prepared from whole brain homogenates and cortex and concurrent absence of Tmem16b transcripts in RNA extracted from brainstem and cerebellum suggests that the gene may be preferentially transcribed in cortexderived neuronal cells.

\section{Biochemical characteristics of TMEM16B}

To characterize the protein encoded by the Tmem $16 b$ mRNA, we raised antibodies to different antigenic regions of the mouse protein. The specificity of the antibodies was demonstrated by Western blotting containing recombinant TMEM16B proteins (Fig. 3A). Both monoclonal antibody TMEM16B-7H10 and polyclonal antibody TMEM16B-303 detected two distinct molecular weight species with electrophoretic mobilities corresponding to $\sim 105$ and $\sim 115 \mathrm{kDa}$ in total cell extracts of 293-EBNA cells overexpressing mouse Tmem16b. In addition, monoclonal antibody TMEM16B-7H10 specifically recognized an epitope in the cytoplasmic N-terminal domain of TMEM16B exemplified by its binding to MBP proteins fused to a N-terminal portion of mouse TMEM16B (amino acids 14-134). In contrast, MBP fused to the intracellular C terminus of TMEM16 (amino acids 950-1002) was recognized by polyclonal antibody TMEM16B-303. The recognition of doublet polypeptides in TMEM16B-transfected cells by different TMEM16B antibodies suggested the occurrence of posttranslational modification(s). Previous reports demonstrated that related proteins TMEM16A (Yang et al., 2008) and TMEM16E (Mizuta et al., 2007) undergo N-glycosylation. TMEM16B contains five putative $\mathrm{N}$-linked glycosylation sites in the extracellular loops with one being highly conserved among the TMEM16 protein family (Fig. 1). Treatment with PNGaseF but not EndoH resulted in a mobility shift of the $115 \mathrm{kDa}$ protein but not the $105 \mathrm{kDa}$ protein species (Fig. 3B), indicating the existence of a complexglycosylated form of TMEM16B. In homogenates from mouse retina and brain, TMEM16B-7H10 detected two proteins migrating at $\sim 105$ and $115 \mathrm{kDa}$, similar to those determined for TMEM16B expressed in 293-EBNA cells (Fig. 3C). TMEM16B was absent from protein lysates prepared from mouse kidney, liver, lung, and heart (data not shown).

In 293-EBNA cells transiently transfected with TMEM16B expression constructs, TMEM16B immunoreactivity was found predominantly concentrated at the plasma membrane (Fig. $3 D$ ). Biochemical extraction studies showed that TMEM16B was sol-

B

Gusb
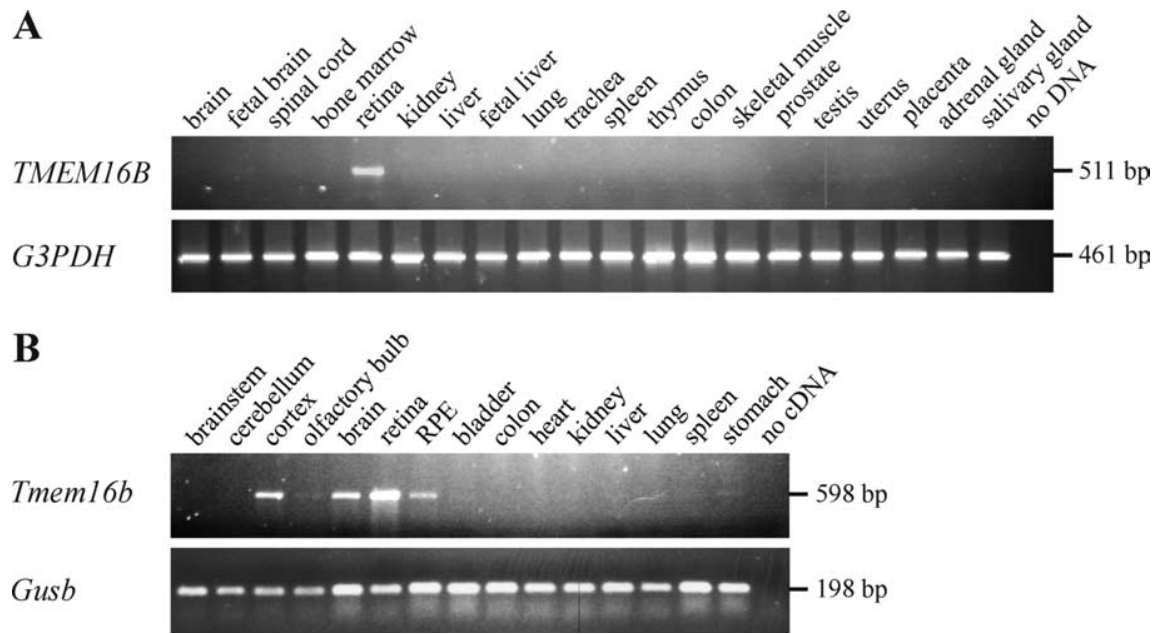

Figure 2. Expression analysis. $A$, RT-PCR assay to analyze TMEM16B expression in a panel of 20 human tissues. G3PDH served as a control. $\boldsymbol{B}, \mathrm{RT}$-PCR to analyze Tmem 16b expression in a panel of 15 mouse tissues. Gusb served as a control.

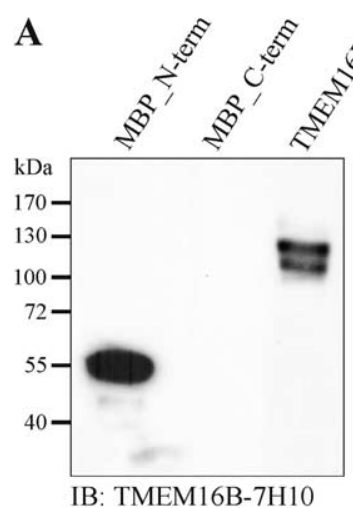

C

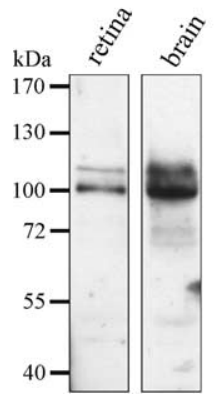

D

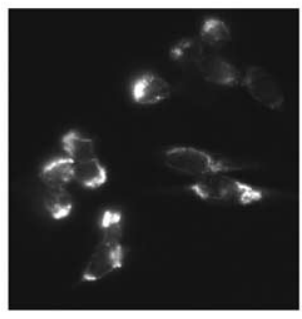

B

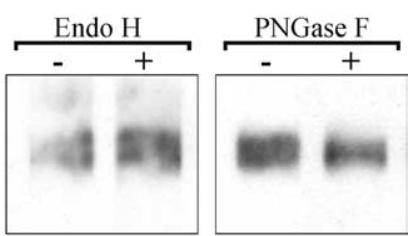

Figure 3. Biochemical properties of TMEM16B. A, Western blot analysis of MBP fusion proteins containing $\mathrm{N}$ - and C-terminal TMEM16B protein fragments and total protein lysates of 293-EBNA cells overexpressing TMEM16B with monoclonal antibody TMEM16B-7H10 and polyclonal antibody TMEM16B-303. B, C, Western blot analysis (B) of TMEM16B immunoprecipitated from 293-EBNA cell after digestion with EndoH and PNGase F glycosidases and $(\boldsymbol{C})$ of TMEM16B in mouse retina and brain homogenates. D, Immunofluorescence detection of TMEM16B in 293-EBNA cells. $\boldsymbol{E}$, Western blot analysis of TMEM16B solubilized with Triton X-100 or SDS. P, Insoluble pellet; S, supernatant. Data shown in $\boldsymbol{B}-\boldsymbol{E}$ were generated with TMEM16B-7H10 antibodies.

ubilized from 293-EBNA cells by anionic detergent SDS but was resistant to Triton X-100 solubilization (Fig. 3E). Together, these observations are consistent with the insertion of TMEM16B glycoproteins into cellular plasma membrane specializations.

TMEM16B localizes to photoreceptor synaptic terminals

Immunofluorescence labeling of frozen mouse retinal sections with the TMEM16B-7H10 antibody produced strong staining of synapses in the outer plexiform layer (OPL) (Fig. 4A). At higher magnification, TMEM16B-7H10 was observed to intensely label 


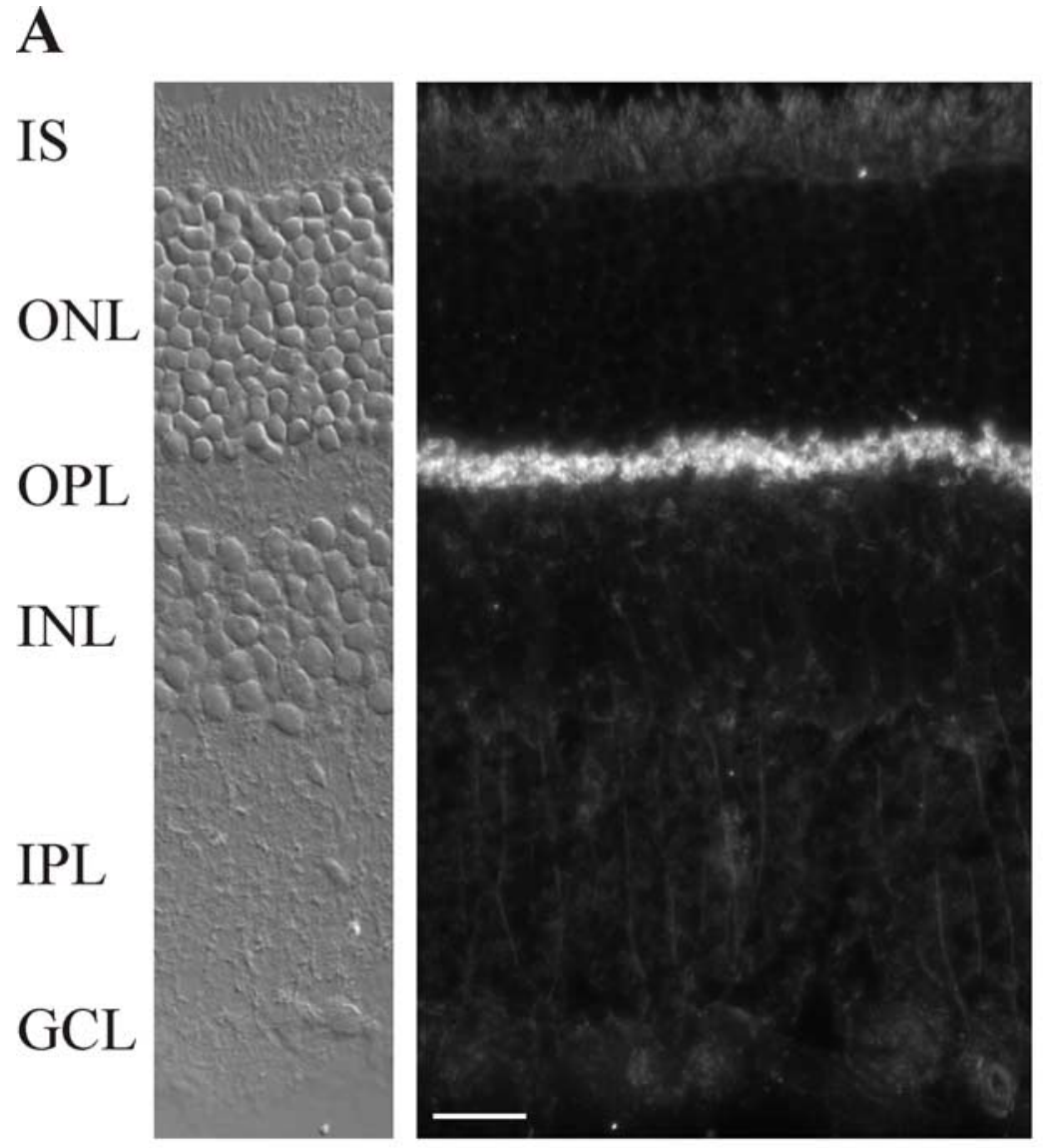

B

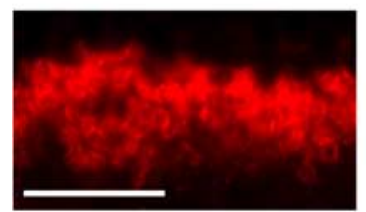

TMEM16B

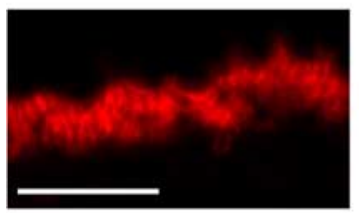

TMEM16B

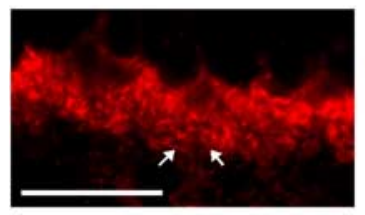

TMEM16B

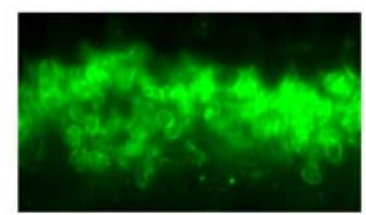

PSD95

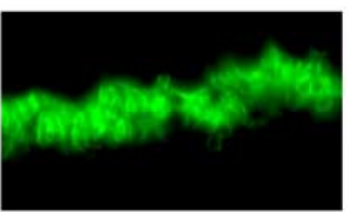

VELI3

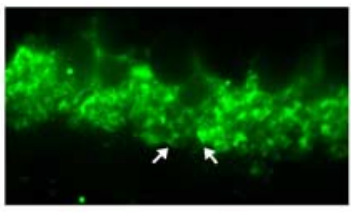

synaptophysin
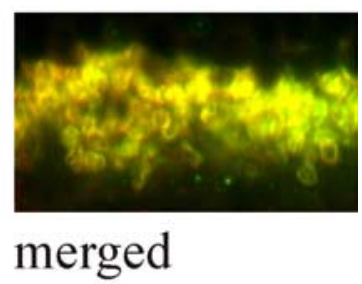

merged

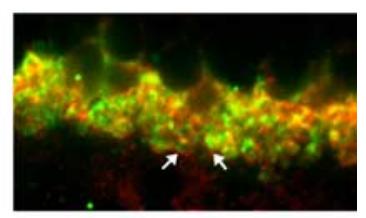

merged

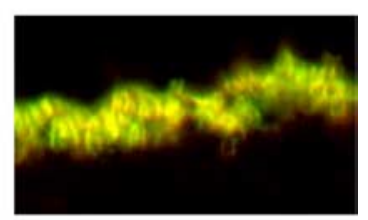

Figure 4. Localization of TMEM16B in mouse retina. $\boldsymbol{A}$, Immunofluorescence microscopy on a cryosection of mouse retina labeled with TMEM16B-7H10. Differential interference contrast image on the left shows the different retinal layers. OS/IS, Outer and inner segments; $0 \mathrm{NL}$, outer nuclear layer; $0 \mathrm{PL}$, outer plexiform layer; INL, inner nuclear layer; IPL, inner plexiform layer; $\mathrm{GCL}$, ganglion cell layer. $\boldsymbol{B}$, Outer plexiform layer simultaneously stained with the TMEM16B-7H10 (red) and antibodies toward PSD95, VELI3, and synaptophysin. Yellow staining in the merged images (right) indicates colocalization. White arrows point to synaptic terminals with plasma membranes labeled by TMEM16B-7H10 (red) and synaptic vesicles stained by synaptophysin antibodies (green). Scale bars: $25 \mu \mathrm{m}$. the membranes of photoreceptor terminals (Fig. $4 B$ ). In contrast, no TMEM16B signals were detected in the inner plexiform layer (IPL), where bipolar cell ribbon synapses are formed (Fig. 4A). Preadsorption of TMEM16B-7H10 with excess of MBP-N-term fusion protein completely abolished the OPL signals (data not shown). Furthermore, exclusive, although weaker labeling of the photoreceptor synapses was also observed when polyclonal TMEM16B-303 antibodies were used for immunohistochemistry (data not shown).

To investigate in more detail the subcellular localization of TMEM16B within the photoreceptor synapse, we compared the TMEM16B staining with markers known to be present in the OPL. PSD95, VELI3, and MPP4 are cytoplasmic adaptor proteins distributed along the plasma membrane of rod spherules and cone pedicles (Koulen et al., 1998; Stöhr et al., 2003, 2005). Double-labeling of mouse retinal sections with TMEM16B-7H10 and antibodies toward any of these adaptors revealed complete overlap of immunoreactivities within the OPL in the merged images (Figs. $4 B, 6$ ). When cryosections were stained with TMEM16B7H10 in conjunction with antibodies toward synaptophysin, a glycoprotein present in the membrane of photoreceptor presynaptic vesicles, the TMEM16B immunoreactivity appeared to be different from the synaptophysin-labeled vesicles (Fig. 4B). These data suggest that TMEM16B is an integrated plasma membrane protein of photoreceptor synaptic terminals.

TMEM16B interacts with PSD95 and is part of a presynaptic protein complex

The three carboxy-terminal amino acids (TNV) of TMEM16B conform to the consensus sequence S/T-X- $\Phi$-COOH (where $\Phi$ is a hydrophobic amino acid and $\mathrm{X}$ is any amino acid) typical for class I PDZbinding motifs (Songyang et al., 1997) (Fig. 1; supplemental Fig. $1 B$, available at www.jneurosci.org as supplemental material). Colocalization of TMEM16B with the PDZ-domain-containing proteins PSD95, VELI3, and MPP4 in the photoreceptor terminals prompted us to test for protein-protein interaction between these molecules. GST fusion proteins containing the C-terminal 53 aa of TMEM16B (GST-TMEM16B-C-term) were used in pulldown assays with PSD95, VELI3, and MPP4 expressed in 293-EBNA cells (Fig. $5 A$ ). The $\mathrm{C}$ terminus of TMEM16B was shown to specifically bind PSD95 which contains three class I PDZ domains. In 
contrast, neither VELI3, a protein with a single class I PDZ domain, nor MPP4, which harbors a class II PDZ domain, was pulled down by the C-terminal sequence of TMEM16B. Furthermore, a TMEM16B deletion mutant lacking the C-terminal three amino acids failed to bind PSD95 (Fig. 5B). Since the C-terminal amino acid residues are most critical for PDZ domain recognition, these results suggested that the $\mathrm{C}$ terminus of TMEM16B serves as a ligand for PDZ domains of PSD95. Moreover, interaction between PSD95 class I PDZ domains and TMEM16B was further confirmed by yeast two-hybrid assays demonstrating that the two N-terminal PDZ domains of PSD95 are able to bind the C terminus of TMEM16B (supplemental Table 1, available at www.jneurosci.org as supplemental material).

In vitro binding assays demonstrated that L27 domain heterodimerization mediates direct interaction between MPP4 and VELI3 (Stöhr et al., 2005), as well as between PSD95 and MPP4 (Förster et al., 2008). Consistent with these results, we show that GST-TMEM16B-C-term pulled down MPP4 in the presence of the L27 domain containing $\beta$-splice variant of PSD95 (Fig. $5 C$ ). We have recently detected the MPP4 protein in PSD95 immunoprecipitates isolated from retinal cytosol (Förster et al., 2008). Immunoprecipitation of PSD95 from SDS detergent-solubilized mouse retinal membranes, however, failed to copurify MPP4 and TMEM16B, suggesting that native interactions between PSD95 and MPP4 as well as between PSD95 and TMEM16B are disrupted by the detergent.

To further investigate a physiological interaction between PSD95 and TMEM16B, we performed immunohistochemical analysis of retinal sections from mice deficient for MPP4 (Mpp4 $\left.{ }^{-/-}\right)$. Previous studies have demonstrated that MPP4 deficiency leads to a loss of PSD95, VELI3, and PMCAs from photoreceptor ribbon synapses (Aartsen et al., 2006; Yang et al., 2007). Labeling of retinal cryosections from $M p p 4^{-/-}$mice with TMEM16B antibodies demonstrated absence of TMEM16B immunoreactivity in the OPL region (Fig. 6), consistent with a loss of TMEM16B from synaptic membranes in the mutant photoreceptors. This strongly suggests that TMEM16B is tethered to the MPP4organized protein network in the photoreceptor synaptic terminals via direct binding to PSD95.

TMEM16B mediates $\mathrm{Ca}^{2+}$-activated anion transport Three independent studies have recently identified TMEM16A to have CaCC activity (Caputo et al., 2008; Schroeder et al., 2008; Yang et al., 2008). Moreover, expression of mouse TMEM16B in

A

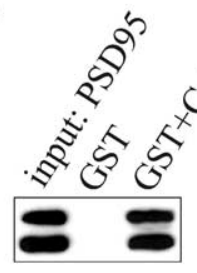

IB: PSD95
IB: MPP4

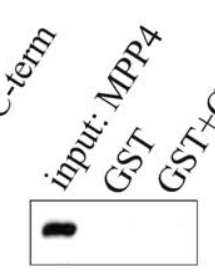

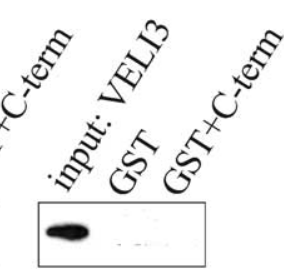

IB: VELI3
B

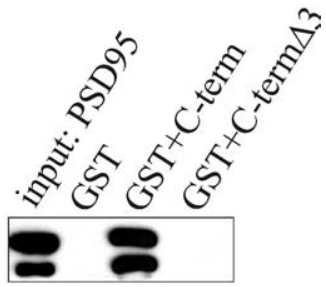

IB: PSD95

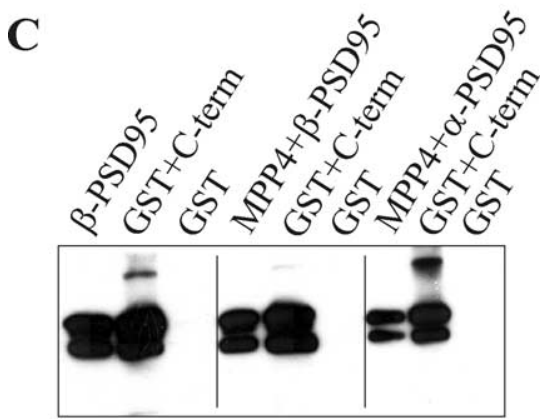

IB: PSD95

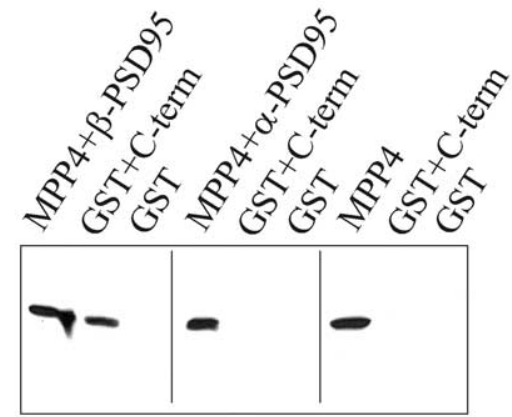

IB: MPP4
Figure 5. Interaction of TMEM16B with PSD95 and MPP4. A, Bacterially expressed GST (control) or GST fusion protein containing the C terminus of TMEM16B (GST + C-term) were incubated with lysates from 293-EBNA cells transfected with PSD95, VELL3, and MPP4. B, GST-pulldown assay performed with a TMEM16B deletion mutant lacking the C-terminal three amino acids (GST + C-term $\Delta 3$ 3). C, GST (control) or GST + C-term fusion proteins were incubated with 293-EBNA cell lysates transfected with $\beta$-PSD95, MPP4 or cotransfected with MPP4 and $\alpha$ - or $\beta$-PSD95. A-C, Bound proteins were identified by immunoblotting with antibodies as indicated below the respective images. Inputs represent $2 \%$ of total cell lysates in all experiments.

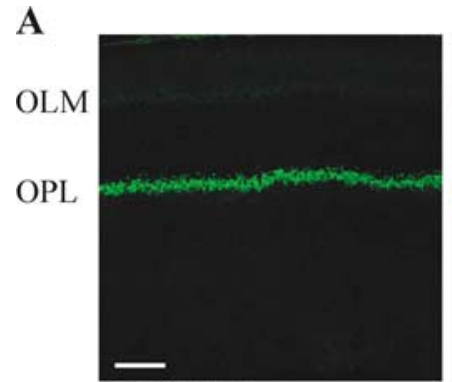

TMEM16B

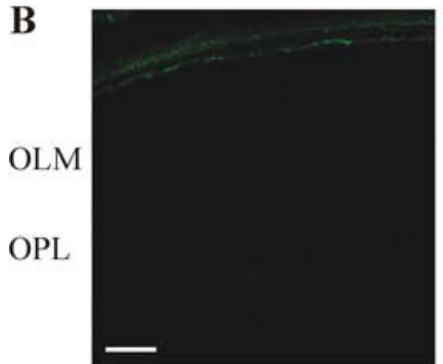

TMEM16B

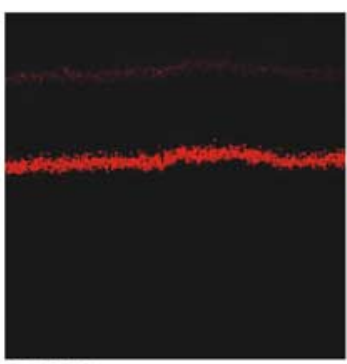

MPP4

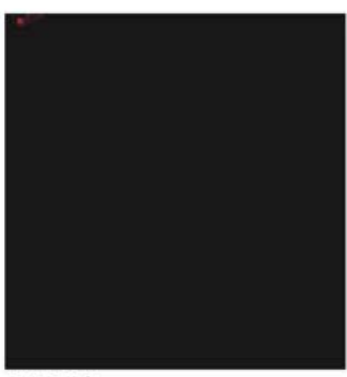

MPP4

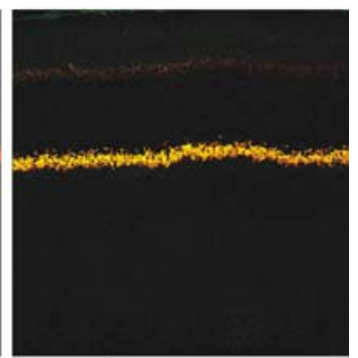

merged

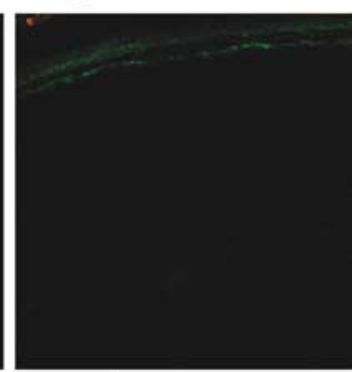

merged
Figure 6. Loss of TMEM16B from Mpp4 $4^{-1-}$ photoreceptor synapses. $A, \boldsymbol{B}$, Retinal sections from wild-type $(\boldsymbol{A})$ and $M p p 4^{-1-}$ mutant $(\boldsymbol{B})$ mice were double-labeled with TMEM16B-7H10 (green) and MPP4 (red) antibodies. Yellow color in the merged wild-type image $(\boldsymbol{A})$ indicates colocalization of TMEM16B and MPP4 in the OPL. Scale bars: $50 \mu \mathrm{m}$.

Axolotl oocytes generated $\mathrm{Ca}^{2+}$-activated chloride currents (Schroeder et al., 2008). To assess for CaCC activity of TMEM16B in mammalian cells, we first performed a halide-sensitive yellow fluorescent protein assay, which is based on fluorescence quenching of YFP-I152L during iodide uptake (Galietta et al., 2001). Application of extracellular $\mathrm{I}^{-}$had no significant effect on the fluorescence in HEK293 cells cotransfected with YFP-I152L and 
A

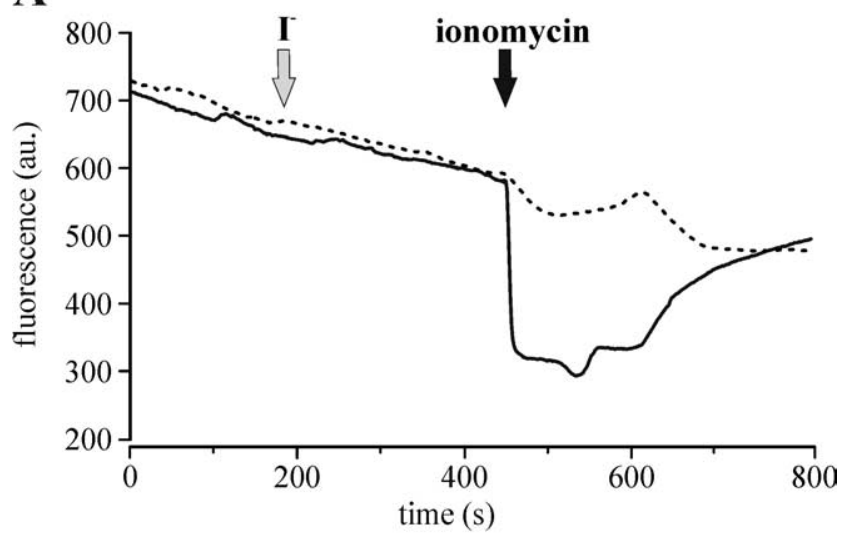

B

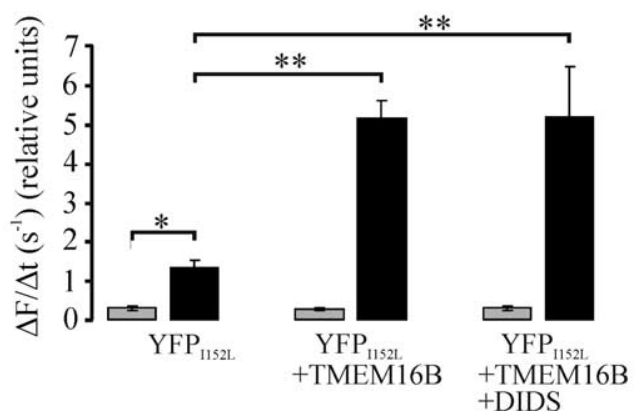

Figure 7. Halide-sensitive YFP assay demonstrates $\mathrm{Ca}^{+2}$-dependent anion conductance in HEK293 cells expressing TMEM16B. A, Representative traces show fluorescence (arbitrary units) in HEK293 cells transfected with YFP-I152L (dashed line) or with YFP-I152L and TMEM16B (solid line). Fluorescence quenching was induced by isotonic application of $20 \mathrm{~mm} \mathrm{I}^{-}$(gray arrow) and $1 \mu \mathrm{m}$ ionomycin (black arrow). $\boldsymbol{B}$, Summary of $\mathrm{I}^{-}$influx-mediated maximal fluorescence quenching (mean \pm SEM). Gray boxes show maximal quenching after the addition of $\mathrm{I}^{-}$, black boxes demonstrate maximal quenching after ionomycin treatment. Addition of ionomycin induced significant fluorescence quenching in all YFP- I152L-transfected cells $\left(^{*} p<0.0001\right.$; paired Student's $t$ test) $(n=51)$. lonomycin-mediated fluorescence quenching was significantly enhanced when YFP-I152L was cotransfected with TMEM16B ( ${ }^{* *} p<0.001$; ANOVA) $(n=61)$. Pretreatment with DIDS had no effect on ionomycin-induced $\mathrm{I}^{-}$influx in cells expressing TMEM16B $(n=31)$.

TMEM16B (Fig. 7A). However, when TMEM16B expressing cells were stimulated with $1 \mu \mathrm{M}$ calcium ionophore ionomycin to raise the intracellular $\mathrm{Ca}^{2+}$ levels, a rapid decrease in cellular fluorescence was repeatedly produced (Fig. 7A). The analysis of $\mathrm{I}^{-}$ influx-mediated maximal fluorescence quenching after elevation of $\mathrm{Ca}^{2+}$ concentration demonstrated that the fluorescence intensity was quenched fourfold in cells expressing TMEM16B/YFPI152L when compared with those expressing only YFP-I152L (Fig. $7 B$ ). The significant reduction of fluorescence in YFPI152L-transfected HEK293 cells after ionomycin application may be explained by activation of endogenous $\mathrm{CaCC}$ resulting from cyotosolic $\mathrm{Ca}^{2+}$ increase.

To test the pharmacological properties of TMEM16B, we added the chloride channel inhibitor DIDS before $\mathrm{I}^{-}$application and found that the TMEM16B-dependent $\mathrm{I}^{-}$uptake was insensitive to DIDS treatment (Fig. $7 B$ ).

\section{Electrophysiological properties of TMEM16B}

To further investigate whether TMEM16B possesses intrinsic chloride channel activity, whole-cell membrane currents were recorded from HEK293 cells transfected with YFP alone or with YFP in combination with TMEM16B. Currents were recorded under settings approximately mimicking physiological conditions (intracellular $30 \mathrm{mM} \mathrm{Cl}^{-}$; extracellular $140 \mathrm{mM} \mathrm{Cl}^{-}$; $\mathrm{E}_{\mathrm{Nernst}}$ $\left.\mathrm{Cl}^{-}=-40 \mathrm{mV}\right)$. Control HEK293 cells transfected with YFP showed negligible currents $(0.46 \pm 0.24 \mathrm{nA}$ at $+50 \mathrm{mV})$ with a reversal potential of $-30.7 \pm 8.2 \mathrm{mV}$ indicating a basic $\mathrm{Cl}^{-}$ conductance (Fig. 8A,C). In contrast, HEK293 cells transfected with TMEM16B evoked outwardly rectifying membrane currents $(1.32 \pm 0.33 \mathrm{nA}$ at $+50 \mathrm{mV})$ with a reversal potential of $-29.9 \pm$ $1.1 \mathrm{mV}$, which is closer to the equilibrium potential for $\mathrm{Cl}^{-}$than to those for $\mathrm{K}^{+}, \mathrm{Na}^{+}$, or a nonspecific cation channel under the selected recording conditions (Fig. $8 \mathrm{~B}, \mathrm{C}$ ). The currents showed a fast activation, which reached steady-state currents after $34 \mathrm{~ms}$ (Fig. $8 \mathrm{~B}$ ). Elevation of free intracellular $\mathrm{Ca}^{2+}$ by ionomycin application dramatically increased TMEM16B induced membrane currents with outward rectification $(252 \pm 42.68 \%)$ and a reversal potential of $-38.15 \pm 1.02 \mathrm{mV}$ (Fig. $8 F, G$ ). This current was absent in HEK293 cells transfected with YFP alone (Fig. 8D,E).

To further test the ion selectivity of TMEM16B induced whole-cell currents, the bath solution was replaced by a low- $\mathrm{Cl}^{-}$Ringer solution that contains $\mathrm{Cl}^{-}$concentration equal to that of the pipette solution. In HEK293 cells overexpressing TMEM16B, substitution of Ringer with low-Cl-Ringer solution reduced the outward current amplitude by $\sim 80 \%$ (Fig. $8 H$ ). In addition, a large shift of the reversal potential to more positive values $(-10.5 \pm 1.2 \mathrm{mV}$ ) was observed (Fig. $8 \mathrm{H}, \mathrm{J})$. The reversal potential with symmetric $\mathrm{Cl}^{-}$solutions is near the range of the equilibrium potential for gluconate anions $(-6 \mathrm{mV})$ suggesting conductance for gluconate. In ionomycin-treated cells, the ionic composition of the extracellular solution was changed to low$\mathrm{Cl}^{-}$-Ringer after the currents reached their maximal amplitudes. $\mathrm{On} \mathrm{Cl}^{-}$replacement, a dramatic reduction of the outward current amplitudes was observed (Fig. $8 I$ ) and the reversal potential shifted to $-11.5 \pm 0.9 \mathrm{mV}$ (Fig. $8 I, J)$. Together, these data indicate that TMEM16B confers selective chloride conductance, which is strongly activated by intracellular $\mathrm{Ca}^{2+}$.

\section{Discussion}

Numerous electrophysiological and imaging experiments have revealed very large $\mathrm{Ca}^{2+}$-activated chloride currents of unknown molecular identity in photoreceptor inner segments. In the present study, we report the identification of TMEM16B, a member of the TMEM16 transmembrane protein family with CaCC activity (Caputo et al., 2008; Schroeder et al., 2008; Yang et al., 2008), which is abundantly present in photoreceptor synaptic membranes. HEK293 cells transfected with TMEM16B showed a basal conductance with outwardly rectifying currents that increased after elevation of free intracellular $\mathrm{Ca}^{2+}$. The reversal potentials of these currents follow the equilibrium potentials for $\mathrm{Cl}^{-}$when different $\mathrm{Cl}^{-}$concentrations were present in the extracellular solution, indicating that the currents were carried by $\mathrm{Cl}^{-}$channel activity. Our electrophysiological data thus confirm earlier studies showing CaCC activity of TMEM16B heterologously expressed in Axolotl oocytes (Schroeder et al., 2008).

Analyzing rods with ablated synaptic terminals, it has recently been shown that $\mathrm{Ca}^{2+}$-activated chloride currents are compartmentalized in the rod terminal, which requires discrete targeting mechanisms that preferentially sort chloride channels to the terminals (MacLeish and Nurse, 2007). The exclusive localization of TMEM16B to presynaptic membranes of photoreceptor terminals and the identification of a network of adaptor proteins capable of anchoring TMEM16B to membrane domains are in solid agreement with these observations. Moreover, kinetic behavior and voltage dependence of TMEM16B is almost identical to pre- 
viously reported $\mathrm{Ca}^{2+}$-dependent $\mathrm{Cl}^{-}$ channel currents obtained from rod or cone whole-cell recordings (Balse et al. 2006). Together, this strongly indicates that we have identified the first $\mathrm{Ca}^{2+}$ activated chloride channel in photoreceptor terminals.

TMEM16B evoked currents measured in this study were found to be different from those mediated by TMEM16A $(\mathrm{Ca}-$ puto et al., 2008; Schroeder et al., 2008; Yang et al., 2008). TMEM16B was activated at lower intracellular $\mathrm{Ca}^{2+}$ concentrations than TMEM16A and TMEM16B currents reached steady-state significantly faster than TMEM16A currents. In contrast to TMEM16A, TMEM16Bdependent $\mathrm{Cl}^{-}$conductance was insensitive to $\mathrm{Cl}^{-}$channel blocker DIDS. The distinct biophysical properties of TMEM16B likely reflect adaption to specific needs required for photoreceptor signal transmission.

Activation kinetics and solid activity at basal intracellular $\mathrm{Ca}^{2+}$ levels suggest that TMEM16B provides a background $\mathrm{Cl}^{-}$ conductance active at $\mathrm{Ca}^{2+}$ concentrations in light and darkness. Regardless of the reported differences of equilibrium potentials for $\mathrm{Cl}^{-}$in rod and cones (Thoreson et al., 2002; Thoreson and Bryson, 2004) and of ambiguities in the values for intracellular $\mathrm{Cl}^{-}$concentrations, the crucial role of $\mathrm{Ca}^{2+}$-dependent $\mathrm{Cl}^{-}$currents as regulators of synaptic transmission at the photoreceptor synapse was demonstrated by complete interruption of transmitter release after extracellular $\mathrm{Cl}^{-}$ removal (Thoreson and Miller, 1996). In addition, $\mathrm{Ca}^{2+}$-dependent action potentials in photoreceptors were sensitive to $\mathrm{Cl}^{-}$channel blockers indicating that $\mathrm{Ca}^{2+}$-dependent $\mathrm{Cl}^{-}$channels contribute to the fine regulation of voltagedependent $\mathrm{Ca}^{2+}$ influx (Maricq and Korenbrot, 1988). Consistent with these findings, the linear correlation between $\mathrm{Ca}^{2+}$ conductance of the inner segment membrane and the membrane potential in the voltage range between light and dark was found to be dependent on a tight feedback interaction between L-type $\mathrm{Ca}^{2+}$ channels and $\mathrm{Ca}^{2+}$-dependent $\mathrm{Cl}^{-}$channels (Thoreson et al., 2003). The molecular identification of TMEM16B as a $\mathrm{Ca}^{2+}$-dependent $\mathrm{Cl}^{-}$channel in photoreceptors represents an important step to unravel the precise role of $\mathrm{CaCC}$ in signal transmission at the first retinal synapse.

Protein networks play a central role in the organization of synaptic terminals in the CNS. Synaptic adaptor proteins form a relatively stable submembranous scaffold with conserved protein binding sites that facilitates the recruitment of a pool of exchanging molecules (e.g., receptors, ion channels) to specific plasma positive values $(p<0.001)(J)$.
B

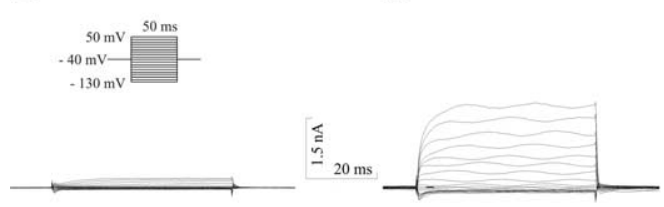

D

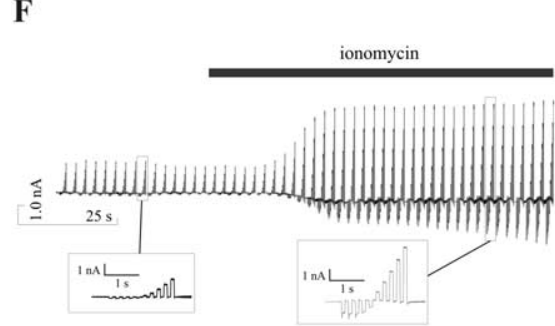

C

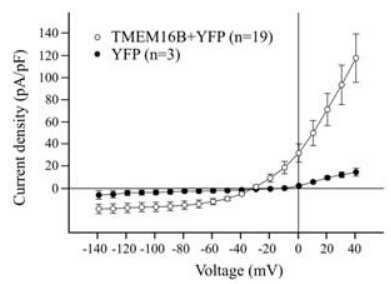

$\mathbf{E}$

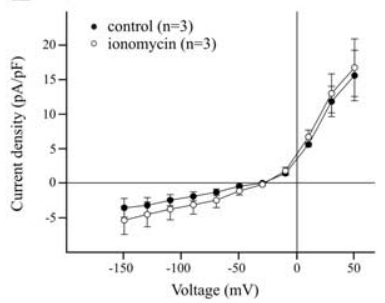

G

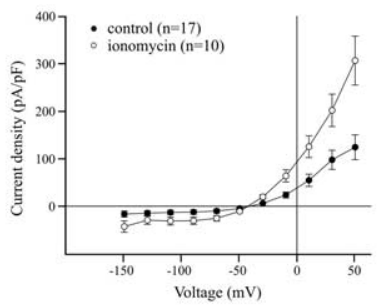

H

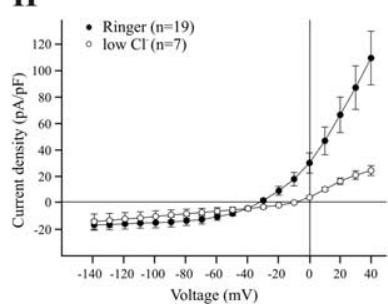

I

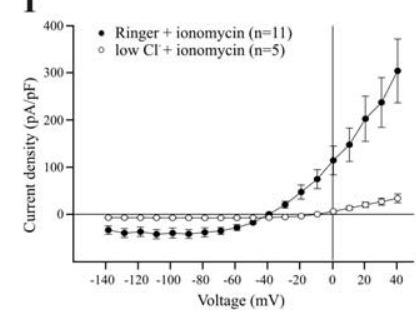

J

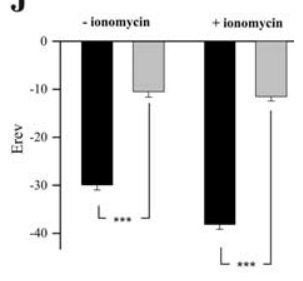

Figure 8. Whole-cell patch-clamp analysis of HEK293 cells expressing TMEM16B. $\boldsymbol{A}, \boldsymbol{B}$, Representative voltage-clamp recordings from a HEK293 cell transfected with YFP $(A)$ and YFP and TMEM16B $(B)$ stimulated with a ramp protocol shown in the inset in A. Membrane potentials were clamped at a holding potential of $-40 \mathrm{mV}$ and the cells were depolarized to $50 \mathrm{mV}$ in $10 \mathrm{mV}$ steps in $50 \mathrm{~ms}$ followed by $-10 \mathrm{mV}$ steps to $-130 \mathrm{mV}$ in $50 \mathrm{~ms}$. Intracellular Ca ${ }^{2+}$ concentration was $100 \mathrm{~nm}$. C, Current-voltage relationships from experiments shown in $\boldsymbol{A}$ and $\boldsymbol{B}$. The currents in the $I-V$ plots are expressed as current densities which were calculated as described previously (Wesolowski et al., 2007). Each value represents the mean current densities ( \pm SEM) measured from cells at each voltage pulse. $\boldsymbol{D}-\mathbf{G}$, Representative voltage-clamp recordings and current-voltage relationships from HEK293 cells transfected with YFP $(\boldsymbol{D}, \boldsymbol{E})$ and YFP and $\operatorname{TMEM} 16 \mathrm{~B}(\boldsymbol{F}, \boldsymbol{G})$ obtained by the protocol shown in the inset in $\boldsymbol{D}$. The membrane currents were continuously recorded at a holding potential of $-40 \mathrm{mV}$ for $125 \mathrm{~s}$. During this time the cells were repeatedly stimulated every $2.5 \mathrm{~s} \mathrm{by}-20 \mathrm{mV}$ voltage steps (each $100 \mathrm{~ms}$ ) to $-140 \mathrm{mV}$ followed by depolarization steps to $60 \mathrm{~mm}$. Treatment with $1 \mu \mathrm{m}$ ionomycin is indicated by black bars. The mean current densities ( \pm SEM) of cells with and without ionomycin application (control) were plotted against the test potentials of the electrical stimulation. Insets in $\boldsymbol{F}$ show magnifications of current deflections obtained with HEK293 cells expressing TMEM16B before and after ionomycin application. $\boldsymbol{H}, \boldsymbol{I}$, Currentvoltage relationships from HEK293 cells transfected with YFP and TMEM16B obtained with Ringer or low- $\mathrm{Cl}^{-}{ }^{-}$-Ringer solution by the protocol shown in $\boldsymbol{A}$. Current-voltage relationship in $\boldsymbol{I}$ was measured after ionomycin application. Replacing Ringer bath solution with symmetric $\mathrm{Cl}^{-}$reduced current amplitudes and caused statistically significant shifts of the reversal potentials to

membrane compartments. We show that the C-terminal region of TMEM16B interacts with PDZ domains of PSD95, the classical adaptor protein in the postsynaptic density of central excitatory synapses. Moreover, PSD95 and the attached adaptor proteins MPP4 and VELI3 appear to act as a presynaptic scaffold to specifically tether TMEM16B to membrane domains along the photoreceptor terminals. Similar to TMEM16B, several "type b" splice variants of the PMCA family have been shown to interact with PDZ domains of PSD95 (DeMarco and Strehler, 2001). 
Among the four PMCA isoforms, PMCA1 and PMCA2 have been demonstrated to colocalize with PSD95 in the OPL (Krizaj et al., 2002; Duncan et al., 2006). TMEM16B and PMCAs are absent from photoreceptor synapses of mice that lack MPP4, possibly because of the loss of PSD95 in the mutant terminals. Although physiological interaction between PSD95 and either PMCA or TMEM16B needs to be confirmed in the retina, it seems likely that simultaneous binding to multivalent PDZ-domain protein PSD95 maintains PMCA and TMEM16B in immediate vicinity within the presynaptic plasma membrane. This cluster may be stabilized through adapter proteins MPP4, VELI3, and other so far unknown proteins by anchoring the complex to the neuronal cytoskeleton or downstream signaling. PMCAs are important for the regulation of free intracellular $\mathrm{Ca}^{2+}$ levels by mediating voltage-independent $\mathrm{Ca}^{2+}$ extrusion from photoreceptor terminals (Krizaj and Copenhagen, 1998; Morgans et al., 1998). Close association of PMCA with TMEM16B could serve to tightly control the CaCC activity of TMEM16B by local fluctuations in $\mathrm{Ca}^{2+}$ concentration. TMEM16B appears to be uniformly expressed throughout the synaptic terminals including the bases of photoreceptor ribbon synapses. PMCA isoforms with different affinities for $\mathrm{Ca}^{2+}$ (Hilfiker et al., 1994) and activation kinetics (Berridge et al., 2003) are selectively distributed to subcellular regions within the rod and cone synapses (Krizaj et al., 2002; Duncan et al., 2006). L-type voltage-gated calcium channels accumulate at the active zone immediately adjacent to the synaptic ribbons (Morgans et al., 1998). Thus, the dynamic interplay between $\mathrm{Ca}^{2+}$ influx and $\mathrm{Ca}^{2+}$ extrusion is likely to determine TMEM16B activity in specific membrane-associated $\mathrm{Ca}^{2+}$ microdomains of the photoreceptor terminals.

Depletion of MPP4 from photoreceptor terminals leads to a disruption of a multiprotein complex exemplified by the absence of presynaptic proteins important for signal transmission. Characterization of two independent MPP4-deficient mice lines has revealed relatively mild phenotypes with minor morphological abnormalities (Aartsen et al., 2006; Yang et al., 2007) and only slightly impaired signal transmission from rods to second-order neurons (Yang et al., 2007). This may be caused by compensatory changes in the expression and distribution of functionally related proteins. Concurrent changes in the expression and distribution of SERCA2, $\mathrm{IP}_{3} \mathrm{RII}$, and recoverin in MPP4-deficient synaptic terminals have been attributed as adaptive responses to increased cytosolic $\mathrm{Ca}^{2+}$ levels induced by PMCA loss (Yang et al., 2007). The TMEM16 family consists of 10 members in humans and mouse (Rock and Harfe, 2008). In addition to TMEM16A, which was found to be expressed in all retinal layers (Yang et al., 2008), several TMEM16 genes ( $\mathrm{C}$ to $\mathrm{F}$ ) are transcribed in mouse retina (H. Stöhr and H. L. Schulz, unpublished data) and thus, represent putative candidates for $\mathrm{CaCC}$ in photoreceptors. Interestingly, only TMEM16B, TMEM16E and TMEM16J possess consensus sites for recognition of type I PDZ proteins. The further characterization of TMEM16B and other retinal members of the TMEM16 family will help to elucidate the physiological function of calcium-activated chloride currents in the retina.

\section{References}

Aartsen WM, Kantardzhieva A, Klooster J, van Rossum AG, van de Pavert SA, Versteeg I, Cardozo BN, Tonagel F, Beck SC, Tanimoto N, Seeliger MW, Wijnholds J (2006) Mpp4 recruits Psd95 and Veli3 towards the photoreceptor synapse. Hum Mol Genet 15:1291-1302.

Bader CR, Bertrand D, Schwartz EA (1982) Voltage-activated and calciumactivated currents studied in solitary rod inner segments from the salamander retina. J Physiol 331:253-284.

Balse E, Tessier LH, Forster V, Roux MJ, Sahel JA, Picaud S (2006) Glycine receptors in a population of adult mammalian cones. J Physiol 571:391-401.

Berridge MJ, Bootman MD, Roderick HL (2003) Calcium signalling: dynamics, homeostasis and remodelling. Nat Rev Mol Cell Biol 4:517-529.

Caputo A, Caci E, Ferrera L, Pedemonte N, Barsanti C, Sondo E, Pfeffer U, Ravazzolo R, Zegarra-Moran O, Galietta LJ (2008) TMEM16A, a membrane protein associated with calcium-dependent chloride channel activity. Science 322:590-594.

Cia D, Bordais A, Varela C, Forster V, Sahel JA, Rendon A, Picaud S (2005) Voltage-gated channels and calcium homeostasis in mammalian rod photoreceptors. J Neurophysiol 93:1468-1475.

Copenhagen DR, Hemilä S, Reuter T (1990) Signal transmission through the dark-adapted retina of the toad (Bufo marinus). Gain, convergence, and signal/noise. J Gen Physiol 95:717-732.

DeMarco SJ, Strehler EE (2001) Plasma membrane Ca2+-atpase isoforms $2 \mathrm{~b}$ and $4 \mathrm{~b}$ interact promiscuously and selectively with members of the membrane-associated guanylate kinase family of PDZ (PSD95/Dlg/ ZO-1) domain-containing proteins. J Biol Chem 276:21594-21600.

Duncan JL, Yang H, Doan T, Silverstein RS, Murphy GJ, Nune G, Liu X, Copenhagen D, Tempel BL, Rieke F, Krizaj D (2006) Scotopic visual signaling in the mouse retina is modulated by high-affinity plasma membrane calcium extrusion. J Neurosci 26:7201-7211.

Förster JR, Lochnit G, Stöhr H (2009) Proteomic analysis of the membrane palmitoylated protein-4 (MPP4)-associated protein complex in the retina. Exp Eye Res 88:39-48.

Galietta LJ, Haggie PM, Verkman AS (2001) Green fluorescent proteinbased halide indicators with improved chloride and iodide affinities. FEBS Lett 499:220-224.

Hilfiker H, Guerini D, Carafoli E (1994) Cloning and expression of isoform 2 of the human plasma membrane Ca2 + ATPase. Functional properties of the enzyme and its splicing products. J Biol Chem 269:26178-26183.

Koulen P, Fletcher EL, Craven SE, Bredt DS, Wässle H (1998) Immunocytochemical localization of the postsynaptic density protein PSD-95 in the mammalian retina. J Neurosci 18:10136-10149.

Krizaj D, Copenhagen DR (1998) Compartmentalization of calcium extrusion mechanisms in the outer and inner segments of photoreceptors. Neuron 21:249-256.

Krizaj D, Copenhagen DR (2002) Calcium regulation in photoreceptors. Front Biosci 7:d2023-d2044.

Krizaj D, Demarco SJ, Johnson J, Strehler EE, Copenhagen DR (2002) Cellspecific expression of plasma membrane calcium ATPase isoforms in retinal neurons. J Comp Neurol 451:1-21.

MacLeish PR, Nurse CA (2007) Ion channel compartments in photoreceptors: evidence from salamander rods with intact and ablated terminals. J Neurophysiol 98:86-95.

Maricq AV, Korenbrot JI (1988) Calcium and calcium-dependent chloride currents generate action potentials in solitary cone photoreceptors. Neuron 1:503-515.

Mizuta K, Tsutsumi S, Inoue H, Sakamoto Y, Miyatake K, Miyawaki K, Noji S, Kamata N, Itakura M (2007) Molecular characterization of GDD1/ TMEM16E, the gene product responsible for autosomal dominant gnathodiaphyseal dysplasia. Biochem Biophys Res Commun 25:126-132.

Morgans CW, El Far O, Berntson A, Wässle H, Taylor WR (1998) Calcium extrusion from mammalian photoreceptor terminals. J Neurosci 18:2467-2474.

Rieke F, Schwartz EA (1996) Asynchronous transmitter release: control of exocytosis and endocytosis at the salamander rod synapse. J Physiol 493:1-8.

Rock JR, Harfe BD (2008) Expression of TMEM16 paralogs during murine embryogenesis. Dev Dyn 237:2566-2574.

Schroeder BC, Cheng T, Jan YN, Jan LY (2008) Expression cloning of TMEM16A as a calcium-activated chloride channel subunit. Cell 134:1019-1029.

Singh A, Hamedinger D, Hoda JC, Gebhart M, Koschak A, Romanin C, Striessnig J (2006) C-terminal modulator controls Ca2+-dependent gating of Ca.(v) 1.4 L-type Ca2+ channels. Nat Neurosci 9:1108-1116.

Songyang Z, Fanning AS, Fu C, Xu J, Marfatia SM, Chishti AH, Crompton A, Chan AC, Anderson JM, Cantley LC (1997) Recognition of unique carboxyl-terminal motifs by distinct PDZ domains. Science 275:73-77.

Stöhr H, Mah N, Schulz HL, Gehrig A, Fröhlich S, Weber BH (2000) EST mining of the UniGene dataset to identify retina-specific genes. Cytogenet Cell Genet 91:267-277. 
Stöhr H, Mohr N, Fröhlich S, Mehdi SQ, Bhattacharya SS, Weber BH (2002) Cloning and characterization of WDR17, a novel WD repeat-containing gene on chromosome 4q34. Biochim Biophys Acta 1579:18-25.

Stöhr H, Stojic J, Weber BH (2003) Cellular localization of the MPP4 protein in the mammalian retina. Invest Ophthalmol Vis Sci 44:5067-5074.

Stöhr H, Molday LL, Molday RS, Weber BH, Biedermann B, Reichenbach A, Krämer F (2005) Membrane-associated guanylate kinase proteins MPP4 and MPP5 associate with Veli3 at distinct intercellular junctions of the neurosensory retina. J Comp Neurol 481:31-41.

Suryanarayanan A, Slaughter MM (2006) Synaptic transmission mediated by internal calcium stores in rod photoreceptors. J Neurosci 26:1759-1766.

Thoreson WB, Bryson EJ (2004) Chloride equilibrium potential in salamander cones. BMC Neurosci 5:53.

Thoreson WB, Miller RF (1996) Removal of extracellular chloride suppresses transmitter release from photoreceptor terminals in the mudpuppy retina. J Gen Physiol 107:631-642.

Thoreson WB, Stella SL Jr, Bryson EI, Clements J, Witkovsky P (2002) D2like dopamine receptors promote interactions between calcium and chloride channels that diminish rod synaptic transfer in the salamander retina. Vis Neurosci 19:235-247.

Thoreson WB, Bryson EJ, Rabl K (2003) Reciprocal interactions between calcium and chloride in rod photoreceptors. J Neurophysiol 90:1747-1753.

van de Pavert SA, Kantardzhieva A, Malysheva A, Meuleman J, Versteeg I, Levelt C, Klooster J, Geiger S, Seeliger MW, Rashbass P, Le Bivic A, Wijnholds J (2004) Crumbs homologue 1 is required for maintenance of photoreceptor cell polarization and adhesion during light exposure. J Cell Sci 117:4169-4177.

Wesolowski R, Sommer A, Arndt HD, Koert U, Reiss P, Wimmers S, Strauss O (2007) Functional studies of synthetic gramicidin hybrid ion channels in $\mathrm{CHO}$ cells. Chembiochem 8:513-520.

Yang J, Pawlyk B, Wen XH, Adamian M, Soloviev M, Michaud N, Zhao Y, Sandberg MA, Makino CL, Li T (2007) Mpp4 is required for proper localization of plasma membrane calcium ATPases and maintenance of calcium homeostasis at the rod photoreceptor synaptic terminals. Hum Mol Genet 16:1017-1029.

Yang YD, Cho H, Koo JY, Tak MH, Cho Y, Shim WS, Park SP, Lee J, Lee B, Kim BM, Raouf R, Shin YK, Oh U (2008) TMEM16A confers receptoractivated calcium-dependent chloride conductance. Nature 455:1210-1215.

Zühlke RD, Pitt GS, Deisseroth K, Tsien RW, Reuter H (1999) Calmodulin supports both inactivation and facilitation of L-type calcium channels. Nature 399:159-162. 